\title{
EL CÓMO Y EL PORQUÉ DE LAS INTERJECCIONES DERIVADAS DE LOS VERBOS DE MOVIMIENTO
}

\author{
SANNE TANGHE \\ Universidad de Gante
}

\begin{abstract}
En los últimos años han proliferado los estudios sobre todo lo que concierne a las interjecciones. No obstante, la mayoría de esos estudios trata de descripciones funcionales o sintácticas de las interjecciones. En este artículo vamos más allá y mostraremos que no es casualidad que las formas verbales anda, vamos, vaya y venga han desarrollado usos interjectivos. Además, se intenta demostrar que estos usos se dejan justificar por el comportamiento semántico-pragmático de las formas verbales originarias. De esta manera, nuestro estudio basado en un corpus coloquial se propone relevar, en primer lugar, los aspectos semántico-pragmáticos de las formas verbales mantenidos en sus usos interjectivos y, luego, trataremos de explicitar las extensiones metafóricas que dan cuenta del desarrollo de estas formas verbales hacia la categoría de las interjecciones.
\end{abstract}

Keywords: interjecciones, verbos de movimiento, lingüística de corpus

\section{Introducción}

En el español coloquial peninsular florece el uso de las partículas anda, vamos, vaya y venga. Son formas verbales que han perdido en menor o mayor medida los rasgos sintácticos y semánticos de sus verbos originarios. Al mismo tiempo, constituyen estrategias discursivas que se han fijado mediante un proceso de gramaticalización ${ }^{1}$, proceso que implica una recategorización (cf. Cuenca y Hilferty 1999, 161). De esta manera acaban por integrarse en la categoría de las interjecciones:

(1) Venga, léenos alguno de ellos, anda. (CREA: Oral; España, 1986)

(2) Enc.- Es que es una cosa, vamos, nunca oída... (MC-NLCH, MA-4)

(3) G: ¡vaya! iqué suerte! oyee enhorabuena (Val.Es.Co; L.15.A.2)

Esta adscripción categorial se justifica por las características que Cuenca (1996; 2000, 35-36) atribuye a las interjecciones y que presentan las partículas anda, vamos, vaya y veng $a^{2}$ :

a) Morfológicamente son fósiles ya que no responden a variación morfológica de género, número, modo o aspecto. La variante ande no se puede considerar como excepción a esta invariablidad morfológica sino como un caso límite entre el uso exclamativo e interjectivo (cf. López Bobo, 2002). Esta variación

\footnotetext{
${ }^{1} \mathrm{El}$ presente estudio no propone profundizar en la discusión sobre el proceso de cambio sufrido por estas partículas. Por eso hacemos uso del término 'gramaticalización' como concepto operativo. Para los principales puntos de vistas y referencias referimos a, entre otros, Company Company (2004, 2008), Cuenca \& Hilferty (1999, cap. 6), Dostie (2004), Heine, Claudi \& Hünnemeyer (1991), Hopper \& Traugott (1993) Marín Jordà (2005), Martins Valle (2000), Ocampo (2006).

2 Sobre las características de la interjección en español se puede consultar también: Alarcos Llorach (1994), Alcaide Lara (1996), Alonso-Cortés (1999), Almela Pérez (1990), Cueto Vallverdú y López Bobo (2003), López Bobo (2002), Torres Sánchez (2000).
} 
morfológica de anda se limita a la oposición indicativo-subjuntivo y nunca sufre, por ejemplo, variación de número: ¡Anda, idos a la calle un rato!. Además, admiten ciertos procesos de derivación como, por ejemplo, la reduplicación ('Vaya, vaya, menuda playa!) y la prefijación.

b) Sintácticamente, las interjecciones se comportan como unidades enfáticas y focales, y suelen tener autonomía distribucional. Esta autonomía explica por qué pueden ocupar ellas solas un turno de palabra (cf. Portolés 1998, 67). A pesar de su autonomía, algunas interjecciones pueden ser seguidas en ocasiones por que átono: Pues anda que mi hermano pequeño me pegó un arañazo (CREA; España: Oral, 1991).

c) Desde un punto de vista pragmático las interjecciones carecen de valor conceptual y tienen significados de naturaleza pragmática. Por tanto, el contexto resulta imprescindible para su interpretación.

El presente estudio se inscribe en el marco cognitivista que parte de un enfoque basado en el uso del lenguaje y que caracteriza el lenguaje como una entidad dinámica en evolución contínua. Según Langacker $(1987,57)$ la gramática es: «un conjunto de rutinas cognitivas, que se constituyen, mantienen y modifican por el uso lingüístico». Partiendo de estos principios básicos, este artículo trata de describir los aspectos semántico-pragmáticos y formales de las formas verbales anda, vamos, vaya y venga que justifican su evolución hacia unidades sumamente pragmáticas con funciones tan diversificadas. De esta manera, se pretende revelar el lazo entre la semántica de las formas verbales originarias y los usos pragmáticos de las interjecciones.

El estudio se organizará alrededor de las tres preguntas de investigación siguientes:

1) ¿En qué medida el aspecto deíctico, inherente a la semántica de los verbos $i r$ y venir, condiciona el uso de las interjecciones vamos, vaya y venga?

2) ¿Qué papel juega el significado de movimiento de estos verbos en el desarrollo de los usos pragmáticos de las interjecciones?

3) ¿Cuáles son los movimientos semánticos que acompañan el proceso de gramaticalización de estas interjecciones?

El análisis se basa en un análisis de corpus del español peninsular coloquial. Este corpus representativo contiene unos 200 ejemplos de cada interjección provenientes de bancos de datos electrónicos (Corpus de Referencia del Español Actual (CREA), Corpus del Espanol (CdE), Corpus de conversaciones coloquiales (Val.Es.Co), Macrocorpus de la norma lingüistica culta de las principales ciudades del mundo hispánico (MC-NLCH)).

En lo que sigue llevaremos a cabo un estudio de los usos que anda, vamos, vaya y venga pueden desempeñar. ${ }^{3}$ Mientras que el uso de vamos ya ha sido descrito ampliamente (entre otros Cortés Rodríguez 1991, Fuentes Rodríguez 1998, Martín Zorraquino/Portolés 1999 y Romero Aguilera 2006) anda, vaya y venga carecen de cualquier análisis semántico-pragmático detenido. En cuanto a las interjecciones anda y vaya, sus análisis se han concentrado sobre todo en una caracterización de sus rasgos sintácticos, particularmente en la construcción con complemento ( $A$ Anda que no soy malo.) (cf. Rodríguez Ramalle 2007 y Sancho Cremades 2006a) y en el uso de vaya como intensificador de un sintagma nominal ( $\mathrm{V}$ Vaya palabrota.) (cf. Octavio de Toledo y Huerta 2001-2002 y Sancho Cremades 2006b). Al lado de estas descripciones, el comportamiento de estas cuatro interjecciones ha sido abordado solo brevemente en obras más generales sobre las interjecciones y los marcadores del discurso (cf. Briz Gómez 1994, Briz Gómez et al. 2008, Edeso Natalías 2009, Landone 2009 y Pons Bordería 1998, Santos Río 2003, etc.), pero falta un análisis integral y comparativo de anda, vamos, vaya y venga.

3 Cabe mencionar que el carácter tan polifacético de estas interjecciones no se deja describir exhaustivamente a partir de nuestra investigación y que este estudio se limita a observar e investigar algunas tendencias en cuanto a los usos de estas cuatro interjecciones. Nunca proponemos como objetivo representar en su totalidad la complicada realidad lingüística de estas unidades. 
No obstante, este trabajo va más alla de la pura descripción empírica e intenta demostrar la regularidad detrás del aparente desorden funcional. Partimos del presupuesto de que las funciones de anda, vamos, vaya y venga dependen en gran medida de la semántica de las formas verbales originarias. Por eso, hace falta detenerse ante todo en la semántica de los verbos andar, ir y venir así como en los aspectos formales (modo, persona y tratamiento) de las formas verbales de las que se han brotado las interjecciones anda, vaya, vamos y venga.

\section{Aspectos semántico-pragmáticos de las formas verbales originarias}

Las cuatro interjecciones sujeto de este estudio derivan todas de una forma verbal en imperativo. ${ }^{4}$ En cuanto a anda, vaya y venga son formas de segunda persona singular del imperativo afirmativo; anda es informal mientras que ande, vaya y venga son más bien formas de cortesía. ${ }^{5}$ Entre las cuatro interjecciones, vamos es el marginado, no solo porque es la única en forma plural sino también porque deriva de una forma medieval del subjuntivo de ir (cf. González Ollé 2002) que aún en la actualidad «se emplea, con más frecuencia que vayamos, con finalidad exhortativa» en términos del Diccionario panhispánico de dudas. ${ }^{6}$

En cuanto a la semántica, estos verbos de movimiento se dejan clasificar en varias categorías semánticas. Así, andar se adscribe a los verbos de modo de desplazamiento mientras que ir y venir se consideran verbos de dirección de desplazamiento (cf. Crego García 2000). Aquellos se caracterizan por expresar inherentemente la manera en que se desplaza sin que el movimiento expresado sea orientado. Por otro lado, los verbos de dirección de desplazamiento, expresan intrínsicamente la dirección del movimiento. En otras palabras, el verbo andar se emplea como respuesta a ¿cómo? mientras que los verbos ir y venir forman parte de una respuesta introducida por combinaciones de una preposición seguida del pronombre interrogativo dónde, tales como ¿a dónde?, ¿̇acia dónde?, etc.

En segundo lugar, la diferencia entre ir y venir, dos verbos de dirección de desplazamiento, reside en la dirección expresada. A saber, ir expresa obligatoriamente alejamiento del hablante $\mathrm{y}$, por lo tanto, es un verbo eferencial mientras que venir expresa acercamiento al hablante por lo que se define como verbo aferencial (cf. Crego García 2000). Además, en español, contrariamente a otras muchas lenguas, el verbo venir requiere la presencia del hablante en el punto de llegada en el momento del enunciado (cf. Tenny 1995). ${ }^{7}$

Finalmente, diferentes autores han observado un vínculo entre la semántica de los verbos venir e ir y el eje temporal: venir se relaciona con el pasado y el verbo ir con el futuro. Efectivamente, ir expresa alejamiento del tiempo del hablante tal como expresa alejamiento del lugar donde está situado el hablante y al revés para venir (cf. Cifuentes

\footnotetext{
${ }^{4}$ Aunque la forma formal ande y la forma informal va también se suelen encontrar en el elenco de las interjecciones deverbales nos hemos limitado en este estudio a las interjecciones más comunes en el habla peninsular. La interjección va resulta menos corriente ya que ni siquiera figura en el Diccionario de particulas (cf. Santos Río 2003). La ausencia de la interjección ande en el Corpus de Referencia del Español Actual (CREA) - en el siglo XX y entre los ejemplos orales - prueba que la forma es mucho menos común que anda con 139 ocurrencias.

${ }^{5}$ Con 'formas de cortesía' referimos a las formas de segunda persona singular del subjuntivo con las que el emisor muestra respecto y consideración frente al oyente de tal manera que las convenciones que rigen una conversación no sean violadas (cf. Haverkate 1994). Así, un estudiante debería usar la forma formal o de cortesía del verbo cuando se dirige a un profesor: ¿Está usted disponible el martes por la tarde? Contrariamente a situaciones informales (entre amigos, en familia, etc.) en las que el emisor se sirve de formas informales del verbo: Hombre, jvete ya!. Con respecto a estas interjecciones solo anda deriva de una forma informal de segunda persona singular de indicativo.

${ }^{6}$ Para una vista general de la evolución histórica que han padecido estas interjecciones, véase entre otros Company Company (2008), Octavio de Toledo y Huerta (2001-2001) y Pons Rodríguez (2010). El estudio actual focaliza en el lazo entre los usos sincrónicos y la semántica de los verbos originarios.

${ }^{7}$ Por consiguiente, cuando una madre llama a su hijo a que venga, el hijo responderá con ; Ya voy! dado que el hijo aún no se sitúa en el punto a que su madre le ha llamado. Por otro lado, en francés, por ejemplo, no se establece la condición de la presencia del hablante en el punto de llegada para el uso del verbo venir, por lo que, el hijo respondrá con Je viens!.
} 
Honrubias 2007, Traugott 1978). La idea de que venir se dirija hacia el pasado e ir hacia el futuro está basada sobre las equivalencias siguientes que implican una extensión de la deixis espacial hacia la deixis temporal (cf. Cifuentes Honrubia 2007, 105):

$$
\begin{aligned}
& \text { VENIR } \rightarrow \rightarrow \rightarrow \text { 'lugar del hablante' } \rightarrow \rightarrow \rightarrow \text { IR } \\
& \text { PASADO } \rightarrow \rightarrow \rightarrow \text { 'tiempo del hablante' } \rightarrow \rightarrow \rightarrow \text { FUTURO }
\end{aligned}
$$

Estos aspectos semántico-pragmáticos de las formas verbales sirven de base para un proceso de gramaticalización que cambiará sustancialmente el comportamiento de estas formas. Sin embargo, argumentaremos que este proceso no impide que varios de estos aspectos se trasluzcan en su comportamiento interjectivo.

\section{Las interjecciones anda, vamos, vaya y venga y sus vínculos con la forma verbal originaria}

Para mantener una visión de conjunto sobre la maraña de usos desempeñados por estas interjecciones, hace falta clasificarlos. Así, a partir de nuestro corpus resulta que es posible distinguir tres clases funcionales generales basadas en el modelo de las funciones del lenguaje propuesto por Bühler (1950) y elaborado por Jakobson (1960). Es de conocimiento general que este modelo parte de los seis elementos inherentes a cualquier acto de comunicación (contexto, mensaje, emisor, receptor, canal de comunicación y el código de la lengua) para relacionar a éstos las seis funciones de la lengua (referencial, poética, expresiva, apelativa, fática y metalingüística respectivamente). En cuanto a las interjecciones derivadas de los verbos de movimiento, del corpus resultará que los usos pueden estar clasificados en tres clases funcionales generales:

(1) Función apelativa, con la que el hablante intenta provocar una reacción en su interlocutor.

(2) Función metadiscursiva cuando el objetivo principal consiste en organizar el discurso.

(3) Función expresiva en estos casos en que el hablante usa la interjección para exteriorizar sus actitudes o estados de ánimo ante la situación extralingüística o lingüística.

Respecto a las funciones que desempeñan posiblemente las interjecciones en nuestro corpus, las primeras observaciones (cf. Cuadro 1) ya revelan algunas

\begin{tabular}{|c|c|c|c|}
\hline & Apelativo & Metadiscursivo & Expresivo \\
\hline \multirow[t]{4}{*}{ Anda } & \multirow[t]{4}{*}{ exhortar } & & afirmación enfática \\
\hline & & & $\begin{array}{l}\text { afirmación enfática } \\
\text { gradual }\end{array}$ \\
\hline & & & protesta \\
\hline & & & sorpresa \\
\hline \multirow[t]{4}{*}{ Vamos } & \multirow[t]{4}{*}{ exhortar } & expletivo & \multirow{2}{*}{$\begin{array}{l}\text { apoyo } \\
\text { enunciativo }\end{array}$} \\
\hline & & matizar & \\
\hline & & comentador & aproximador \\
\hline & & reformulador & protesta \\
\hline \multirow[t]{3}{*}{ Vaya } & & matizar & afirmación enfática \\
\hline & & \multirow[t]{2}{*}{ comentador } & $\begin{array}{l}\text { cuantificador } \\
\text { exclamativo }\end{array}$ \\
\hline & & & evidencia \\
\hline
\end{tabular}
diferencias notables, que serán discutidas más en detalle a lo largo de este artículo: 


\begin{tabular}{|l|l|l|l|}
\hline & & reformulador & protesta \\
\cline { 3 - 4 } & & & sorpresa \\
\hline Venga & exhortar & (pre)clausura & acuerdo \\
\hline \multicolumn{3}{|c|}{ Cuadro 1. Los valores de las interjecciones }
\end{tabular}

Según Traugott y König $(1991,189)$ las tres funciones indicadas se sitúan en un cline 'una línea' del proceso de cambio lingüístico:

«from meanings grounded in more or less objectively identifiable extralinguistic situations to meanings grounded in text-making (for example connectives, anaphoric markers, etc.) to meanings grounded in the speaker's attitude to or belief about what is said, $[\ldots] . »$

En otras palabras, el uso apelativo es el primer uso que se suele manifestar en un proceso de pragmaticalización. Luego la forma pragmaticalizada puede evolucionar hasta poseer un uso textual e incluso expresivo.

En los apartados siguientes describimos en detalle y siguiendo el cline del proceso de pragmaticalización, todos los usos de anda, vamos, vaya y venga observados en el corpus y, además, se examina en qué medida estos usos se dejan explicar por el carácter semántico-pragmático de las formas verbales originarias.

\subsection{Los usos apelativos}

Las interjecciones con función apelativa ya no ordenan al interlocutor que ejecute la acción de movimiento presente en la semántica de los verbos originarios. Por haber sufrido un proceso de gramaticalización, suelen reforzar la exhortación expresada por un imperativo u otro recurso lingüístico o extralingǘstico (como los gestos) que acompaña la interjección. En otros términos, estas interjecciones han perdido su valor semántico originario de movimiento pero mantienen de una manera mitigada la carga directiva del imperativo (cf. Traugott y Dasher 2002).

Las cuatro interjecciones derivan de una forma verbal para expresar la incitación (el imperativo). A pesar de ello, resulta que vaya nunca refuerza la exhortación en nuestro corpus:

(4) Doña Camelia vamos a dejarlo a dejarla terminar. Habla anda si tienes valor, habla. (CREA: oral; España, 1996)

(5) Bien Merche, vamos cuenta tu historia, por favor. (CREA: oral; España, 1996)

(6) V: Smuy bonito/ jvenga!/ enséñame las del cuarto de baño $\uparrow /$ si las tienes (Val.ES.CO; IH.340.A.1)

Este comportamiento desviante de vaya se explica a partir de la ausencia en su forma del aspecto semántico de proximidad entre los interlocutores ${ }^{8}$. Este aspecto semántico es requerido para poder cumplir una función apelativa ya que con este uso la interjección no solo sirve para reforzar la exhortación sino que al mismo tiempo ayuda a proteger la imagen positiva del hablante, es decir el deseo que tiene el locutor de que su identidad y personalidad sean apreciadas y aprobadas (cf. Brown y Levinson 1987). Así, si omitimos la interjección en el ejemplo (6) enséñame las del cuarto de baño, la orden expresada por el imperativo jsigue! vuelve mucho más directa y puede, por tanto, constituir un acto amenazador de la imagen positiva del hablante. Dicho de otra manera, el interlocutor puede considerarlo como un agravio o una señal de desprecio

\footnotetext{
${ }^{8}$ Esta afirmación no implica que vaya como interjección nunca pudiera haber tenido un uso apelativo sino que en la actualidad esta función probablemente ha caído en desuso (si con todo ha tenido un uso apelativo). Proponemos que la carencia de esta función se deja explicar por la ausencia en su forma o semántica originaria de un aspecto de proximidad que procura proteger la imagen positiva del hablante. Este aspecto semántico-pragmático forma una parte esencial de la función apelativa de las interjecciones derivadas de los verbos de movimiento (al lado de reforzar la exhortación).
} 
por parte del hablante lo que, a su vez, desfavorece la postura positiva del interlocutor para con el hablante. De ahí que el hablante añada una interjección, en este caso venga, que permite mitigar tal ataque a su imagen positiva.

Contrariamente a vaya, las interjecciones anda, vamos y venga comportan un aspecto deíctico que disminuye la distancia social y crea un ambiente de familiaridad entre los hablantes, lo que propicia la proximidad entre los interlocutores (cf. Landone 2009; Solano Rojas 1989). En primer lugar, anda se manifiesta como interjección en su forma informal, un registro que se suele utilizar en situaciones de familiaridad entre los interlocutores, o sea, interviene en este caso la deixis social ${ }^{9}$. En cuanto a la interjección vamos, influye la deixis personal visto que el plural evoca una implicación de la primera y segunda persona. ${ }^{10}$ Finalmente, como venir requiere la presencia del hablante en el punto de llegada en el momento del enunciado, la forma venga atrae al interlocutor hacia sí lo que, a su vez, constituye un indicio de relaciones sociales próximas entre los interlocutores.

En suma, las interjecciones anda, vamos y venga permiten subrayar la exhortación y al mismo tiempo proteger la imagen positiva del hablante por la presencia de un aspecto deíctico -espacial, personal o social- que favorece la proximidad entre los interlocutores.

\subsection{Los usos metadiscursivos}

Para clarificar esta función cabe enfatizar la distinción entre una categoría gramatical y una clase funcional. Las interjecciones se consideran como una clase gramatical caracterizada por una serie de propiedades particulares mientras que los marcadores del discurso constituyen una clase funcional que Martín Zorraquino y Portolés $(1999,4057)$ definen de la manera siguiente:

«Los marcadores del discurso son unidades lingüísticas invariables, no ejercen una función sintáctica en el marco de la predicación oracional y poseen un cometido coincidente en el discurso: el de guiar, de acuerdo con sus distintas propiedades morfosintácticas, semánticas y pragmáticas, las inferencias que se realizan en la comunicación.»

Esta definición implica que varias categorías gramaticales pueden funcionar como marcadores del discurso, o sea referir al discurso mismo y, por lo tanto, revelar los mecanismos de creación y estructuración de la conversación. Así, unidades lingüísticas pertenecientes a varias clases gramaticales como los adverbios (sin embargo, entonces, etc.), las conjunciones (pero, pues, etc.) y las interjecciones tal como vamos, vaya y venga admiten un uso metadiscursivo (Nunca bebo alcohol, vamos, casi nunca bebo alcohol.). En otras palabras, no todas las unidades con una función de marcador del discurso pertenecen a la clase de las interjecciones, ni todas las partículas que pertenecen a la clase de las interjecciones son marcadores del discurso ya que también pueden desempeñar una función apelativa o expresiva ${ }^{11}$.

Como se puede observar en el cuadro 1, solo la interjección anda nunca figura en el corpus como marcador del discurso. Esto se explica por el hecho de que anda es la única interjección que deriva de un verbo de movimiento no-deíctico. Por otra parte, consideramos que del valor semántico de dirección inherentemente presente en los verbos ir y venir, perdura cierto matiz en los marcadores derivados (cf. Romero

\footnotetext{
${ }^{9}$ La deixis social refiere a la información social codificada en las expresiones lingüísticas (cf. Levinson 1983). Como, por ejemplo, el tratamiento honorífico, lo que implica el uso de palabras marcadas con otros morfemas o de otro léxico dependiente del estatuto social de los interlocutores.

${ }^{10}$ En español es imposible usar la forma de la primera persona plural de imperativo sin que el oyente esté incluido en la acción (cf. Dobrushina/Goussev 2005, 186).

11 Para una descripción de las diferencias y semejanzas entre marcadores del discurso e interjecciones referimos a Edeso Natalías (2009), López Bobo (2002), Portolés (1998) y Vázquez Veiga (2003) entre otros.
} 
Aguilera 2006). Es decir, el valor de dirección ha pasado del dominio de la deixis espacial al dominio de la deixis discursiva. ${ }^{12}$ Esta extensión puede explicarse a partir de la metáfora propuesta por Romero Aguilera (2006) 'el discurso es un viaje'. Esta metáfora se relaciona con la metáfora 'argumentar es seguir una trayectoria' propuesta por Lakoff/Espenson/Schwartz (1991). Una de las submetáforas es 'argumentos son trayectorias en las que viajan pensamientos' ya que se puede decir, por ejemplo, 'interrumpir el curso de pensamientos' o también 'no puedo seguir lo que está diciendo'. Pues bien, dado que en los verbos ir y venir predomina la presencia de la trayectoria en su semántica, frente a andar como verbo de modo de desplazamiento, son aquellos verbos los que son capaces de guíar al interlocutor a lo largo de la trayectoria que es el discurso.

Es además, una extensión bien conocida ya que Heine/Claudi/Hünnemeyer (1991, 182) señalan que la metáfora 'espacio-hacia-discurso', o sea la gramaticalización a través de la línea deixis espacial > referencia temporal > deixis textual se manifiesta en varias lenguas. ${ }^{13}$ Dentro de esta extensión metafórica los usos metadiscursivos de vamos, vaya y venga se dejan explicar por varios aspectos semántico-pragmáticos de las formas verbales originarias.

\subsubsection{Ir es movimiento hacia el porvenir, venir es movimiento hacia el pasado (dominio espacial - dominio temporal - dominio discursivo)}

Para empezar resulta que vamos y vaya admiten un uso reformulativo, es decir, pueden presentar el enunciado que introducen como una nueva formulación del enunciado anterior (cf. Martín Zorraquino/Portolés 1999). La interjección introduce o bien una explicación $(7,9)$ o bien una rectificación (8) del miembro anterior:

(7) Tengo que pasarme un fin de semana allí para enterarme a ver cómo están de precios todo aquello de una casa de piedra que no esté muy bien, tampoco me o sea, que esté bien, vamos, que se pueda arreglar (CREA: oral; España, s.d.)

(8) [...], y esta noche vamos a ir a cenar a mi casa, vamos, a la casa de mis padres, porque con eso de mi casa o casa de mis padres te armas un taco terrible, $[\ldots]$ (MC-NLCH, MA-3)

(9) Y lo que yo también una idea que yo tenía era que, bueno, en España siempre se ha creado de todo, siempre hemos estado creando, siempre hemos sido creativos, vaya. (CREA: oral; España, 1992)

En la ilustración (8) vamos sustituye el enunciado anterior, que presenta como una formulación incorrecta, por otra que la mejora o incluso la corrige (cf. Portolés 2001).

De todos modos, con un uso reformulativo la interjección indica al interlocutor que para la interpretación del resto de la conversación tiene que basarse en lo que sigue a la interjección. Dicho de otra manera, la interjección guía la atención del interlocutor hacia lo que sigue, o sea hacia el porvenir del discurso. Esta inclinación hacia el futuro no es de extrañar dada la ya citada vinculación del verbo ir con la expresión del futuro.

Por la misma razón, vamos admite un uso expletivo. Según Pons Bordería (1998) los expletivos expresan la continuación de un pensamiento que se está formulando y, por lo tanto, se ocupan de la planificación discursiva. También pretende que con este valor pueden no poseer función alguna porque no añaden nada más al discurso y que, por eso, se dejan suprimir. Sin embargo, los expletivos permiten dar tiempo al hablante

\footnotetext{
${ }^{12}$ La deixis discursiva o textual implica las formas lingüísticas que remiten a partes de la conversación misma (cf. Levinson 1983).

${ }^{13}$ La misma tendencia metafórica se encuentra en latín, francés, turco y alemán. Los autores dan el ejemplo español de la distinción espacial entre los demostrativos próximos (este, etc.) y los demostrativos lejanos que conocen una transferencia al mundo del discurso para poder describir distinción anafórica entre un referente mencionado anteriormente y uno mencionado posteriormente (cf. Heine/Claudi/Hünnemeyer 1991, 182).
} 
para organizar su discurso o para buscar la expresión apropiada. Además, al mismo tiempo, vamos asume una función fática: el hablante indica con un expletivo que quiere mantener el turno de habla como muestra el ejemplo siguiente:

(10) En el libro que yo tengo dice eso, que... vamos que toda la gente, todas las representaciones pictóricas que se han hecho a San Juan siempre lo representaban así como haciendo una advertencia: "Si no lo sabes, pues cállate niño" (CREA: oral; España, 1997)

Por consiguiente, los expletivos, tanto como otros muchos usos de las interjecciones, sí se pueden suprimir lo que, sin embargo, conlleva una pérdida del matiz pragmático en la conversación. En otros términos, la posible omisión de una interjección aún no implica que sirva simplemente para rellenar un vacío discursivo sin añadir información imprescindible para la conversación. En fin, el uso expletivo es un síntoma de una característica inherente a la lengua coloquial que se caracteriza, entre otras casos, por la planificación en curso. De cualquier manera, la interjección vamos con un uso expletivo otra vez manda el discurso hacia lo que sigue, igual que el uso reformulativo de esta interjección.

Finalmente, como marcador del discurso vamos puede indicar que el enunciado precedente es un mero comentario sobre el contenido esencial del discurso (11). La interjección vamos comparte este uso comentador con vaya (12):

(11) La primera vez que fui a Madrid estaba vamos, una de las una de la eme cuarenta, no me acuerdo si era en la eme cuarenta, y vamos, iba medio perdido, y pregunté por bueno, llevamos una lo que es una emisora de radioaficionado para eso, para preguntar, para bueno, para echarte el rato muchas veces, $[\ldots]$ (CREA: oral; España, s.d.)

(12) ¿Es esa su técnica? Bueno, cuando yo era más joven y no es que sea muy viejo, vaya, pero en fin, cuando era más joven solía pensar que pues que había que aprender técnicas y tal, [...]. (CREA: oral; España, 1990)

En los ejemplos anteriores las interjecciones indican que el enunciado precedente refiere a una observación personal. El comentario que precede vamos o vaya interrumpe el flujo de la conversación y la interjección indica que lo que precede es un comentario no esencial para el proseguimiento del discurso porque no forma parte del hilo conductor de la conversación. Pues bien, como vamos y vaya derivan de un verbo que expresa inherentemente alejamiento del hablante considerado como centro deíctico, las interjecciones derivadas expresan metafóricamente alejamiento del foco, o sea de lo esencial.

Tal como las interjecciones derivadas del verbo ir, la interjección derivada del verbo aferencial venir también nos guía en nuestro viaje a través del discurso. Sin embargo, venga no está implicado en el proseguimiento del discurso ya que indica una clausura o preclausura de un tema discursivo o de la conversación misma:

(13) José Antonio, muchísimas gracias por contarnos tantas cosas, y dentro de un rato establecemos de nuevo contacto con ese centro de pantallas del Ayuntamiento. Venga, hasta luego. Antes de seguir contándoles más cosas [...] (CREA: oral; España, 1991)

La diferencia entre los usos metadiscursivos de las interjecciones derivadas de los dos verbos reside en la diferencia en el tiempo de referencia implicado en el uso de los verbos. De esta manera, Nakazawa (2007) observa que el tiempo de referencia de ir es el tiempo de llegada o de salida mientras que para venir solo puede ser el tiempo de llegada. Por consiguiente, en español, cuando se dice viene a las ocho al colegio solo puede significar que llega a las ocho al colegio, en otras palabras, venir siempre implica una llegada. 
Además, el verbo venir se vincula con el pasado ya que expresa acercamiento al lugar del hablante igual que expresa acercamiento al tiempo del hablante (cf. Cifuentes Honrubia 2007, Traugott 1978). Esta característica en combinación con el hecho de que venir inherentemente implica una llegada justifica el uso de venga para indicar una (pre)clausura. Además, la metáfora propuesta por Radden (1995) 'fin de evento es fin de trayectoria', en la que venir señala el fin del evento y la trayectoria es el discurso, también da cuenta de este uso metadiscursivo de venga.

En fin, una extensión de la deixis espacial hacia la deixis discursiva o textual posibilita el uso metadiscursivo de vaya, vamos y venga. Sin embargo, por su naturaleza deíctica las interjecciones derivadas del verbo ir están implicadas en el proseguimiento del discurso mientras que venga indica la (pre)clausura de un tema conversacional.

\subsubsection{Ir es alejamiento (dominio espacial - dominio discursivo)}

Las dos interjecciones derivadas del verbo ir pueden introducir una matización del enunciado que precede, es decir el hablante puede introducir con vamos y vaya circunstancias o detalles que precisen el contenido de la unidad comunicativa anterior.

La interjección vamos suele señalarle al interlocutor que en el enunciado precedente el locutor expone su propio punto de vista. La interjección efectúa esta matización introduciendo un comentario en que explícitamente comunica que acaba de expresar su opinión o perspectiva:

(14) $[\ldots]$ en La Primera de Televisión Española, ayer por la noche, sobre la Moncloa, pero realmente sobre Aznar ¿no? y que pareció, vamos, a mí al menos me pareció, una especie de publirreportaje, ¿no? (CREA: Oral; España, 1997)

Un uso matizador particular de vamos, y para vaya es incluso el único uso matizador, consiste en su combinación con la conjunción pero. Precedidas por la conjunción pero las interjecciones suelen matizar el enunciado anterior atenuándolo. Es decir, el hablante niega o afirma algo y con pero vamos o pero vaya introduce una matización. Las interjecciones refuerzan pues el significado de pero que, según la Teoría de Argumentación (cf. Anscombre, J. C./Ducrot, O. 1994), introduce un argumento antiorientado y con más fuerza que el argumento que le precede. Así, en el ejemplo 15, el hablante le cuenta al interlocutor que el documento más antiguo que tienen es una muestra de papiro de antes de Cristo. Este hecho hubiera podido impresionar al interlocutor por su antigüedad si el hablante no hubiera moderado sus palabras diciéndole que la colección de muestra de papiros no es demasiado buena de calidad.

(15) ¿Cuál es el más antiguo? Pues tenemos incluso alguna muestra de papiros de antes de Cristo, pero vamos, no es una colección demasiado buena. (CREA: Oral; España, 1999)

En el ejemplo siguiente el hablante niega que su arte de nadar sea magnífico pero admite que tampoco es deplorable. De esta manera, la combinatoria pero vaya matiza el contenido del enunciado que precede a la interjección:

(16) Pues, no es que nade muy eso, pero vaya, nado bien, o sea me defiendo muy bien. (CREA: oral; España, s.d.)

No es de extrañar que las interjecciones derivadas del verbo ir se empleen con un uso matizador ya que el verbo básico expresa alejamiento del centro deíctico. Como los usos de las interjecciones metadiscursivas se dirigen hacia el discurso, el centro deíctico de vamos y vaya es parte del discurso o es el discurso mismo. De ahí que, cuando vamos indica que lo que precede no es algo aceptado generalmente sino su propio punto de vista, indica que conviene distanciarse en cierta medida del contenido del enunciado anterior y considerarlo de nuevo con, en mente, la nueva información 
dada posteriormente a la interjección. En otras palabras, las interjecciones otra vez remiten a lo que sigue en el discurso, o sea al 'futuro'. De esta manera, en combinación con el conector pero, estas interjecciones ponen de relieve la mayor fuerza argumentativa del enunciado que les sigue.

En segundo lugar, el alejamiento del centro dé́ctico, en el caso concreto el discurso mismo, también se encuentra en el uso comentador de las interjecciones vamos y vaya como arriba mencionado (cf. \$2.3.1.). Considérese otra vez el ejemplo 11 (cf. \$2.3.1.) en el que vaya sigue a un comentario personal que no considera como esencial para el proseguimiento del discurso. Precisamente porque vaya y vamos mantienen este aspecto de alejamiento del centro deíctico, estas interjecciones pueden señalar un distanciamiento del argumento principal de la conversación. Además, en combinación con el aspecto de movimiento hacia adelante, estas interjecciones se encuentran después de este comentario personal o desvío para asegurar un fluido proseguimiento del discurso.

En suma, la metáfora 'ir es alejamiento' repercute en los usos de las interjecciones derivadas, de tal manera que son utilizadas para matizar o bien un enunciado entero o para reforzar el significado matizador de pero. Dicho de otra manera, la extensión del aspecto de alejamiento desde el dominio espacial hacia el dominio del discurso justifica el uso matizador de las interjecciones vamos y vaya.

\subsubsection{Vamos es viajar juntos (dominio personal - dominio discursivo)}

Como ya mencionado anteriormente (cf. $\ I I)$, desde el punto de vista de su morfología, vamos consituye el marginado entre las interjecciones bajo consideración ya que deriva de la primera persona plural del verbo ir. Esta particularidad conlleva que la interjección manifiesta otro comportamiento pragmático en el discurso. En consecuencia, aunque ambas derivan del mismo verbo, vamos presenta un uso metadiscursivo ausente en vaya, a saber el uso expletivo (cf. \$3.2.1.).

Constatamos que con este uso de la interjección el hablante no solo pregunta que el interlocutor dirija la mirada hacia lo que sigue sino que también involucra al hablante en la creación y estructuración del discurso. Así, Martín Zorraquino/ Portolés Lázaro (1999, 4177-4178) afirman que es a través de la primera persona verbal incluida en su forma que vamos «trata de favorecer la comunión, con su propio discurso, de los participantes en la conversación, al incluirlos en la misma esfera enunciativa». En otras palabras, vamos trata de organizar el discurso conforme a lo que intenta comunicar el hablante $y$, al mismo tiempo, trata de involucrar al hablante en esta organización discursiva, o sea «busca la complicidad o la co-participación con el interlocutor» (cf. Martín Zorraquino/Portolés Lázaro 1999, 4180). En pocas palabras, parece que vaya ha explotado sobre todo el aspecto de alejamiento del significado de ir mientras que vamos se diferencia de vaya por las personas incluidas en su forma y, por lo tanto, revela otro abanico de posibilidades funcionales.

El cuadro siguiente resume los aspectos semánticos de la deixis y del movimiento con sus respectivos extensiones metafóricas que justifican los usos discursivos de las interjecciones:

\begin{tabular}{|c|c|c|}
\hline & deixis & movimiento \\
\hline $\begin{array}{l}\text { Valor metadiscursivo } \\
\text { (vamos, vaya, venga) }\end{array}$ & & $\begin{array}{l}\text { Movimiento que implica } \\
\text { una dirección } \\
>\text { 'el discurso es un viaje' (cf. } \\
\text { Romero Aguilera 2006) } \\
>\text { 'argumentar es seguir una } \\
\text { trayectoria' (cf. } \\
\text { Lakoff/Espenson/Schwartz } \\
\text { 1991) } \\
>\text { 'argumentos son trayectorias }\end{array}$ \\
\hline
\end{tabular}




\begin{tabular}{|c|c|c|}
\hline & & $\begin{array}{l}\text { en las que viajan pensamientos' } \\
\text { (cf. } \\
\text { Lakoff/Espenson/Schwartz } \\
\text { 1991) }\end{array}$ \\
\hline $\begin{array}{l}\text { Reformulador } \\
\text { (vamos, vaya) } \\
\text { Expletivo } \\
\text { (vamos) } \\
\text { Matizar } \\
\text { (vamos, vaya) }\end{array}$ & $\begin{array}{l}\text { Deixis espacial } \\
>\text { 'alejamiento/acercamiento } \\
\text { del lugar donde está situado el } \\
\text { bablante es } \\
\text { alejamiento/ acercamiento del } \\
\text { tiempo del hablante' (cf. } \\
\text { Cifuentes Honrubias } \\
\text { 2007, Traugott 1978) }\end{array}$ & \\
\hline $\begin{array}{l}\text { Comentador } \\
\text { (vamos, vaya) }\end{array}$ & $\begin{array}{l}>\text { 'alejamiento del centro } \\
\text { deictico es alejamiento de lo } \\
\text { esencial' }\end{array}$ & \\
\hline $\begin{array}{l}\text { (pre)clausura } \\
\text { (venga) }\end{array}$ & $\begin{array}{l}\text { Deixis espacial } \\
>\text { 'alejamiento/ acercamiento } \\
\text { del lugar donde está situado el } \\
\text { bablante es } \\
\text { alejamiento/acercamiento del } \\
\text { tiempo del hablante' (cf. } \\
\text { Cifuentes Honrubias } \\
\text { 2007, Traugott 1978) }\end{array}$ & $\begin{array}{l}\text { Tiempo de referencia es } \\
\text { tiempo de salida o de } \\
\text { llegada } \\
>\text { 'fin de evento es fin de } \\
\text { trayectoria' (cf. Radden 1995) }\end{array}$ \\
\hline $\begin{array}{l}\text { Expletivo } \\
\text { (vamos) }\end{array}$ & $\begin{array}{l}\text { Deixis personal: la } \\
\text { presencia o no del oyente } \\
\text { en la forma verbal } \\
>\text { 'vamos es colaborar' }\end{array}$ & \\
\hline
\end{tabular}

Cuadro 2. Los usos metadiscursivos y sus extensiones metafóricas

\subsection{Los usos expresivos}

Del corpus resulta que las cuatro interjecciones pueden indicar la actitud del hablante (cf. cuadro 1), o sea desempeñar una función expresiva. No es de extrañar que las interjecciones derivadas de los verbos de movimiento puedan indicar el estado cognitivo o emocional del hablante ya que Sweetser $(1990,28)$ constata que la experiencia corporal, como por ejemplo el movimiento, es una fuente para el vocabulario de los estados psicológicos. Veremos que esta metáfora 'la mente como cuerpo' da cuenta de algunas funciones expresivas cumplidas por estas interjecciones ya que los aspectos de movimiento y dirección presentes en la semántica de los verbos originarios se reflejan en los usos expresivos (sorpresa, protesta, etc.) que anda, vamos, vaya y venga pueden cumplir. Más especificamente, la metáfora 'emoción es movimiento' y su alternativa 'cambio de estado es cambio de lugar' (cf. Lakoff/ Espenson/ Schwartz 1991) justifican el uso de los verbos de movimiento para indicar la actitud del hablante. En lo que sigue, discutiremos las metáforas específicas que posibilitan los varios usos expresivos de las interjecciones.

\subsubsection{Vamos es colaborar (dominio personal - dominio cognitivo)}

En cuanto a la interjección vamos ya hemos señalado que es la única interjección que deriva de una forma verbal de primera persona plural, por lo que muestra un comportamiento deíctico personal divergente. En relación a los usos expresivos de vamos resulta que su forma de segunda persona plural le permite, en primer lugar, funcionar como 'aproximador':

(17) La verdad, me parece que vamos vamos que estamos meando fuera de tiesto. (CREA: oral; España, 1997) 
Con una función 'aproximadora' de la interjección el hablante indica que el enunciado que sigue es su propia manera de formular o expresar algo y, además, suele señalar que esta formulación puede parecer poco apropiada al interlocutor. Este uso se explica por la pragmática de la interjección puesto que incluye a los interlocutores en la misma esfera comunicativa y como resultado busca la complicidad con el interlocutor (cf. Martín Zorraquino/Portolés 1999). Por consiguiente, el hablante puede servirse de la interjección para preguntarle o convencerle al interlocutor de que siga su razonamiento, esto es emplear vamos con un uso aproximador.

En segundo lugar, siguiendo el mismo modo de pensar esta interjección también permite enfatizar la opinión del hablante $\mathrm{y}$, a la vez, por la forma de primera persona plural es capaz de intentar implicar al interlocutor en su propio punto de vista o su manera de pensar:

(18) Es por hacer algo diferente, porque, realmente, de verdad que a mí salir andando y darme la vuelta y volverme, me aburre mucho, vamos. (CREA: oral; España, 1996)

En el ejemplo anterior el hablante indica que las actividades enumeradas le aburren y, posponiendo la interjección, intenta involucrar al interlocutor en su manera de pensar. El uso de vamos que apoya la opinión de su emisor ha sido denominado 'apoyo modalenunciativo' por Fuentes Rodríguez (1998).

En pocas palabras, ha tenido lugar una transferencia del dominio de la deixis personal hacia el dominio cognitivo por lo que vamos procura la colaboración entre los interlocutores.

\subsubsection{Ir es alejamiento, venir es acercamiento (dominio espacial - dominio cognitivo)}

Como postulado más arriba (cf. \$2), el verbo eferencial ir expresa alejamiento del centro deíctico, frente a venir que indica acercamiento por la presencia obligatoria del hablante en el punto de llegada en el momento del enunciado, o sea venir siempre expresa un movimiento hacia el hablante. En consecuencia, por la extensión metafórica desde lo espacial hacia lo psicológico, venga puede indicar que el enunciado que precede se acerca a la opinión o a las ideas del hablante, esto es, expresa el acuerdo. Dicho de otra manera, el movimiento hacia el lugar donde está el hablante se ha transferido a un acercamiento al estado cognitivo del hablante. Consideremos el ejemplo (16) en que el hablante expresa su conformidad con el hecho de que el interlocutor quiere la cristalería:

(19) ¿La cristalería? Pues, venga, otra cristalería otra cristalería de Famosa. (CREA: oral; España, 1991)

Planteamos la hipótesis de que por la misma razón, es decir la oposición entre alejamiento y acercamiento, venga no indica la protesta en el corpus, contrariamente a vaya, vamos y anda. ${ }^{14}$ Un ejemplo concreto permite ilustrar esta idea:

(20) "pero sí son equivalentes", digo, "anda, ¿y por qué voy a ponerle ese rollo?" y efectivamente había que ponerlo así. (CREA: oral; España, s.d.)

Las interjecciones vaya y vamos inherentemente expresan un alejamiento del centro deíctico mientras que anda permite expresarlo. La extensión metafórica, es decir la transferencia del alejamiento del lugar donde se sitúa el hablante al alejamiento de las opiniones o ideas del hablante no cuadra para venga ya que solo puede expresar un movimiento hacia el centro deíctico.

\footnotetext{
${ }^{14}$ Dado que andar permite expresar un alejamiento del hablante, asimismo permite un uso expresivo de protesta.
} 
A continuación, veremos que las interjecciones vaya y anda (ya que, frente a vamos, éstas no incluyen a los interlocutores en la misma esfera comunicativa) prolongan esta extensión metafórica más allá.

\subsubsection{Alejamiento es desviación (dominio espacial - dominio cognitivo)}

Ya sabemos que solo las interjecciones derivadas de andar e ir-que pueden expresar alejamiento del hablante- pueden expresar protesta. Pues bien, notamos en el corpus que se prefiere las interjecciones anda y vaya para indicar una actitud de sorpresa por parte del hablante. Consideramos los ejemplos siguientes:

(21) E: no $\downarrow$ es que con las tapas [de los yogures $\rightarrow=$ ]

L:

E: tengo diez $\downarrow$ me faltan $\operatorname{dos} \int$

[¿cuánto tienes?]

L:

G:

Sianda!S

L:

Siqué regalo! ¿eh?

(Val.Es.Co; L.15.A.2)

Siqué bien!

(22) ¿con quién tengo el gusto de hablar? Esto - yo soy - el primo de Coco, y ¡Vaya! ¡La familia! ¡Dios mío! (Corpus del español: oral; España, s.d.)

En la primera ilustración el hablante se muestra asombrado del hecho de que el interlocutor ya tenga tantas tapas de yogures. En el segundo ejemplo vaya indica que el hablante está sorprendido por estar hablando con un pariente de Coco.

Una persona suele sorprenderse cuando es conmovida, suspendida, maravillada con algo imprevisto, en suma, cuando se plantea una situación inesperada. Como los verbos andar e ir pueden o deben expresar alejamiento, focalizan la fuente del movimiento, contrariamente a venir que suele focalizar la meta del movimiento. En otros términos, éste presenta un esquema terminativo y áquellos pueden demostrar un esquema de desviación (cf. Radden 1995, 444). Radden (1995) propone, además, la metáfora ‘cambio imprevisto de resultado es desviación', en otras palabras, solo los verbos andar e ir que presentan un esquema de desviación pueden indicar un cambio imprevisto de resultado. Por eso, solo las interjecciones derivadas de estos verbos pueden expresar la sorpresa dado que la actidud de sorpresa es una reacción ante una situación imprevista. Por consiguiente, el uso de vaya en el ejemplo (22) es parafraseable de la manera siguiente: "Esta situación con lo que acaba de toparme o, esta información que acabo de enterar, y que no esperaba se encuentra tan lejos de mis expectativas".

Otra metáfora que justifica el uso de anda y vaya para indicar sorpresa es 'cambio de estado es cambio de dirección’ ya que se puede decir, por ejemplo, volverse loco (cf. Lakoff/Espenson/Schwartz 1991). De ahí que solo las formas verbales que admiten un cambio repentino de dirección - tal como ir y andar ya que focalizan la fuente de movimiento (cf. Radden 1995) - admitan dar cuenta de un cambio de estado y de la reacción del hablante ante este cambio.

Finalmente, del corpus se desprende que vamos difícilmente permite indicar la sorpresa pese a que también deriva del verbo ir. Esto se explica por su forma de primera persona plural, que incluye tanto los interlocutores como el hablante en el discurso. En otros términos, la interjección vamos trata de provocar una mayor implicación del hablante y de los interlocutores en el discurso. Por esta implicación del hablante, resulta que se da preferencia a otras interjecciones que vamos para expresar el asombro ante la desviación del trayecto previsto del discurso.

Otro uso de vaya que hemos constatado en nuestro corpus y que se relaciona con la sorpresa y el esquema de desviación de ir, es la indicación del hablante de que el contenido de cierto enunciado le parece evidente, como en el ejemplo siguiente: 
(23) El la vieja amistad la habéis recordado, ¿no? Sí. Oye, el libro ¿dónde has puesto el libro? Pues desde luego, vaya Desde luego (CREA: oral; España, 1996)

Aquí la interjección vaya realza la expresión de evidencia desde luego que señala que al hablante le parece obvio que alguien recuerda la vieja amistad. Igual que el uso comentador de vaya (cf. \$3.2.1.), la interjección indica alejamiento del foco, es decir en el ejemplo (19) el hablante indica al interlocutor que le parece una pregunta casi superflua ya que la respuesta es obvia y no necesita mucha reflexión. En otros términos, como vaya admite expresar la desviación, asimismo puede realzar que el contenido de cierto enunciado consitituye información obvia y conocida por ambos interlocutores.

Dicho esto, Octavio de Toledo y Huerta (2001-2002) considera que el uso de vaya para afirmar enfáticamente el complemento que sigue (introducido por que) se relaciona con el uso para indicar una actitud de sorpresa mencionada arriba. Además de vaya, del corpus resulta que anda admite un uso muy similar, como muestran los ejemplos siguientes:

(24) J: [Me] llamó ayer/ ((porque le duelen los pies))S C: $\quad \int$ janda que le ((duelan los pies))!// y el- y el tío Luisito también le ha dao la paliza a ti\(Val.Es.Co; G.68.B.1+G.69.A.1)

(25) $[\ldots]$, pues salieron para ahí, anda anda que no mató, porque aquel tiraba muy bien a la escopeta y ellos le iban a ojear le fueron a ojear. (CREA: oral; España, 1991)

El autor considera que a partir de vaya que expresa la sorpresa se desarrolló un uso como 'marcador intensivo ante un enunciado' (Vaya, que se casa.) y que por un reanálisis vaya puede funcionar también como 'marcador intensivo focal interno al enunciado' ('Vaya que se casa.). Como estos usos derivan del uso para indicar sorpresa, solo las interjecciones anda y vaya admiten un uso de afirmación enfática. Sin embargo, parece que la construcción con vaya es muy poco frecuente dado que solo topamos con una ocurrencia en nuestro corpus. ${ }^{15}$

En primer lugar, cabe decir que en las construcciones de anda con complemento es frecuente la presencia de no (cf. ejemplo 22): en casi la mitad de las ocurrencias de esta construcción anda afirma una oración en que está presente la partícula de negación no. Sancho Cremades (2006a) considera que la partícula no ha perdido su carga negativa y que su uso es puramente irónico. Según explica el autor, esta ironía proviene del origen de la construcción anda + que + complemento que originó como enunciado en eco (María no es simpática. -iAnda que no es simpática Maria.). Este se ha gramaticalizado y convencionalizado de tal manera que Sancho Cremades (2006a, 2059) asume que: «la negación ya no establece la falsedad del enunciado sino que tiene un valor ponderativo, de carácter pragmático». ${ }^{16}$

Además, constatamos que a partir de este uso de afirmación enfática anda y vaya han conocido una evolución divergente. Respecto a anda, a partir de la afirmación enfática se ha desarrollado el uso de anda como afirmación enfática gradual. El aspecto gradual implica un matiz superlativo que se ha desarrollado a partir del aspecto enfático de la construccion descrita arriba. Esta función es exclusiva de la interjección anda y se

15 Aunque Octavio Toledo y Huerta (2001-2002) describe exclusivamente la construcción vaya más complemento introducido por que damos por supuesto que tanto la evolución de la construcción con anda como la de vaya hacia un marcador intensivo focal interno al enunciado es paralela dado que ambas pueden indicar una actitud de sorpresa, función en la que se basa el uso enfático.

${ }^{16}$ Cabe señalar que la ironía, como también el empleo de la negación para realizar afirmaciones enfáticas, es un recurso típico de la expresividad del registro coloquial (cf. Briz 1998, 123), como en iTienes tù poco dinero!. 
construye con un complemento que siempre es un pronombre personal encabezado por que:

(26) Este puente he debido de engordar dos kilos, de verdad. Pues anda que yo No he hecho más que comer y estar sentada al ordenador. (CREA: oral; España, 1991)

En el ejemplo anterior anda que yo implica una afirmación enfática de carácter gradual que se apoya en el enunciado previo emitido por el interlocutor y que se deja parafrasear por 'yo también he tenido que engordar dos kilos e incluso más' (cf. Rodríguez Ramalle 2007). En realidad, la interjección sitúa el referente del pronombre personal en una escala en la que el referente siempre se encuentra en una posición más alta respecto al sujeto de la oración anterior.

Por otra parte, respecto a la evolución de la interjección vaya, que no presenta el matiz gradual, Octavio de Toledo y Huerta (2001-2002) describe cómo su gramaticalización va aún más lejos y se reanaliza hasta convertirse en lo que el autor denomina 'foco exclamativo en un sintagma nominal intensificado' hasta convertirse en 'cuantificador exclamativo intensivo de nombres'. Los dos ejemplos siguientes ilustran estos usos respectivamente:

(27) Ya, ¿y el otro medio? La banda de Empastre. vaya un lío, ¿no? (CREA: oral; España, 1991)

(28) A: [...] (y en seguida quitó la caja $\uparrow$ y dice jvaya reloj! $\mathrm{Y}$ dice pues si este relos es buenísimo) [...] (Val.Es.Co; RB.37.B.1)

Varios autores proponen que en la construcción vaya $+S N$, ilustrada por los dos ejemplos anteriores, vaya se comporta como una palabra exclamativa tal como qué (cf. Octavio de Toledo y Huerta 2001-2002; Company Company 2008). No obstante, en nuestro corpus hemos constatado algunas diferencias entre el uso de vaya como intensificador y el comportamiento de qué como ha sido descrito en la literatura. ${ }^{17}$ En primer lugar, como señala Sancho Cremades (2006b) el exclamativo qué funciona como especificador dentro del SN visto que no admite especificadores en combinación con el sustantivo que intensifica (*iQué una casa tiene!). ${ }^{18}$ Por otro lado, en nuestro corpus hemos constatado que el SN que sigue a vaya puede contener un especificador que es un artículo, un demostrativo o un posesivo. Por consiguiente, en estos casos el sitio del especificador ya está ocupado, por lo que la interjección debe ser externo al SN (véase ejemplo (27)).

Encima, la presencia del especificador en el SN de vaya $+S N$ no cambia el significado básico de la interjección, o sea intensificar el nombre. Es más bien otro recurso de intensificación o realce pragmático (cf. Briz Gómez, 1998).

Nuestro corpus revela una segunda diferencia entre el comportamiento de vaya y qué exclamativo en este contexto: vaya intensificador se combina exclusivamente con sustantivos o con adjetivos sustantivados, frente a qué que puede preceder, y por lo tanto, intensificar también a adjetivos e incluso a adverbios. El ejemplo siguiente ilustra un uso de vaya seguido directamente por un adjetivo que se emplea como sustantivo:

(29) Eso también lo va a oír luego, a lo mejor. Pues vaya soso que es entonces. (CREA: oral; España, s.d.)

De esta manera, por la presencia del adjetivo grande, una exclamación como ?Vaya grande casa tiene resulta inaceptable gramaticalmente, contrariamente a iQué grande casa

17 Para una discusión más elaborada sobre el uso y la evolución de vaya como intensificador véanse Tanghe (en prensa).

18 De acuerdo con la teoría X' y el enfoque generativista, un sintagma no puede contener más de un especificador. 
que tiene!. Por consiguiente, parece que vaya puede intensificar una propiedad atribuible al sustantivo que le sigue y esta propiedad, además, no debe explicitarse formalmente en la conversación sino que es deducible del contexto lingüístico o extralingüístico. En otras palabras, vaya puede intensificar una propiedad del sustantivo presente implícitamente en el co- o contexto:

(30) Pues te pincho las ruedas si no sacas el coche. Tato oye, para, ¡oye, que es una broma, tío, que es una broma, para, que es una broma, tío. Ven aquí, tío. De hombre, vaya crédito que tienes (CREA: oral; España, 1995)

Del contexto del ejemplo (30) se puede deducir que el interlocutor es bastante ingenuo y por lo tanto tiene fe ciega en lo que dice la gente, así, vaya afirma enfáticamente que el interlocutor tiene alto crédito. Otra posibilidad es que tenga una interpretación irónica y que el interlocutor tenga poco crédito.

En fin, consideramos que vaya como intensificador de sustantivos no pertenece a la categoría gramatical de cuantificadores sino que sigue siendo una interjección que puede funcionar como cuantificador exclamativo. Además, no se puede equiparar con el cuantificador exclamativo qué visto que muestran otras posibilidades combinatorias. En segundo lugar, parece que vaya, contrariamente al qué exclamativo (*iQué una casa que tienen!), no siempre funciona como especificador dado que el sustantivo intensificado ya puede llevar especificador ( $V$ Vaya una casa!).

A lo anterior se debe añadir que en el corpus hemos constatado que la interjección vaya ante todo intensifica el carácter negativo de un nombre o de un sintagma nominal. Octavio de Toledo y Huerta (2001-2002) propone que el significado de actitud negativa proviene de los contextos en que se ha originada la construcción: un participante introduce un tema (vaya un ejemplo) que su interlocutor parodia irónicamente, y al mismo tiempo pondera ( $\mathrm{Oh}$, sí, ;V aya un ejemplo.) porque tiene un desarrollo no esperado por el interlocutor. La actitud negativa en esta parodia se convencionaliza y vaya termina por incluir cierta ironía. Nuestra propuesta es que esta actitud negativa no se ha desarollado por casualidad en la interjección vaya sino que se relaciona con la semántica del verbo originario y más particularmente con el hecho de que ir implica un alejamiento de la primera persona, siendo el término negativo de la deixis. Tal como hemos señalado respecto a la expresión de protesta, alejamiento del hablante implica lejanía de las expectativas y opiniones del hablante, de ahí la alta frecuencia del valor negativo implicado en el uso de vaya en la construcción vaya $+S N$.

A fin de cuentas, el uso enfático y el uso cuantitativo de las interjecciones anda y vaya derivan por un proceso de gramaticalización de la expresión de sorpresa. Además, la ponderación irónica en combinación con el aspecto semántico de alejamiento de la primera persona presente en el verbo ir procura que vaya suele intensificar, particularmente, las cualidades negativas del nombre o del sintagma nominal al que precede. En el cuadro sinóptico 3 están representados los aspectos semánticos y las extensiones metafóricas que consideramos responsables para los valores expresivos de las interjecciones:

\begin{tabular}{|c|c|c|}
\hline & deixis & movimiento \\
\hline $\begin{array}{l}\text { Valor expresivo } \\
\text { (anda, vamos, vaya, venga) }\end{array}$ & & $\begin{array}{l}\text { Verbos de movimiento } \\
>\text { 'la mente como cuerpo' } \\
>\text { 'emoción es movimiento' } \\
>\text { 'cambio de estado es cambio de } \\
\text { lugar' (cf. Lakoff/Espenson/ } \\
\text { Schwartz) }\end{array}$ \\
\hline $\begin{array}{l}\text { Sorpresa } \\
\text { (anda, vaya) } \\
\text { Evidencia } \\
\text { (vaya) }\end{array}$ & $\begin{array}{l}\text { Deixis espacial } \\
>\quad \text { 'cambio imprevisto de } \\
\text { resultado es desviación' } \\
\text { (cf. Radden 1995) }\end{array}$ & \\
\hline Protesta & Deixis espacial & \\
\hline
\end{tabular}




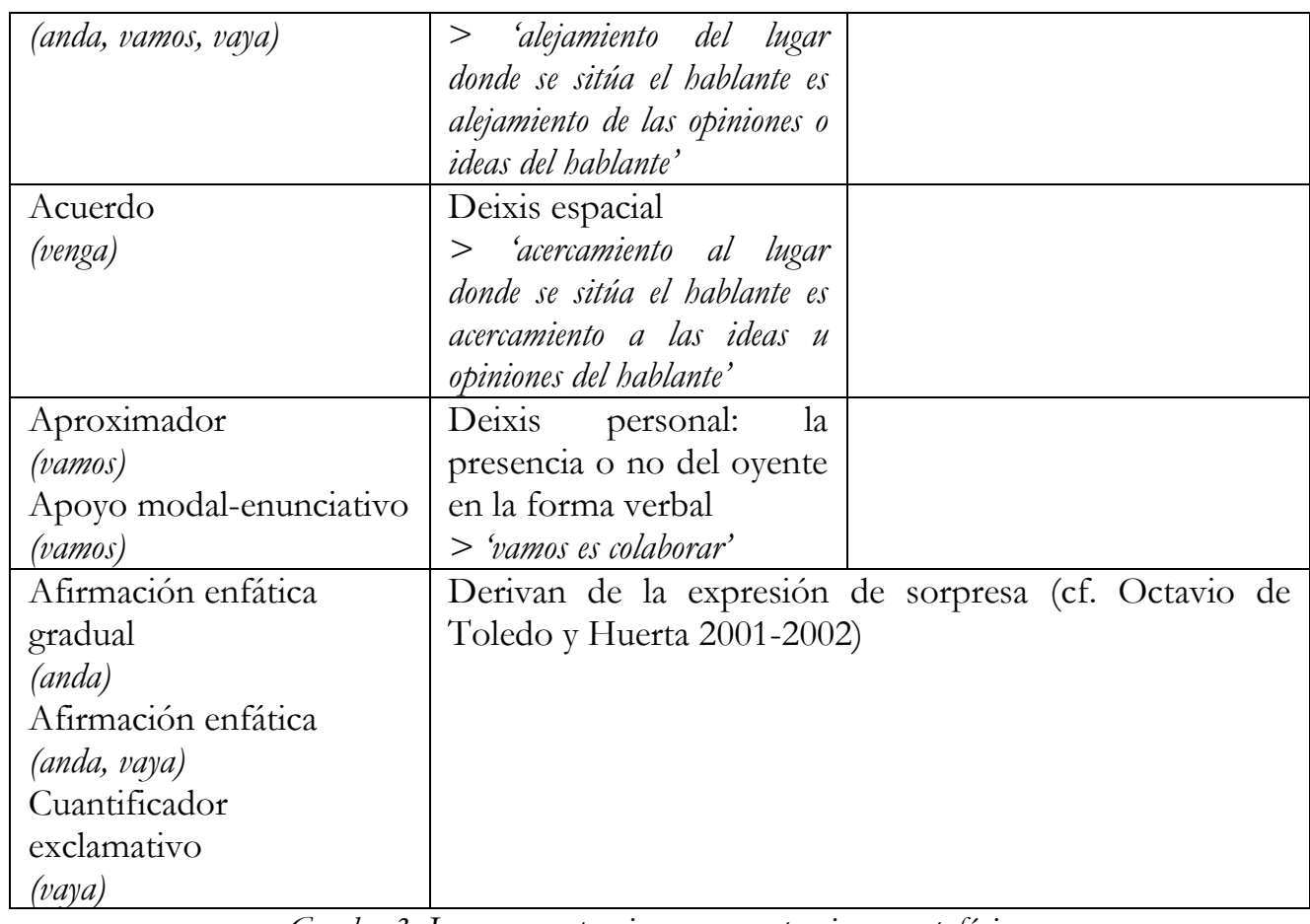

Cuadro 3. Los usos expresivos y sus extensiones metafóricas

\section{Consideraciones Finales}

Como es bien sabido las interjecciones son unidades polifuncionales, resultado de un proceso de gramaticalización. Como este proceso trascurre gradualmente, el grado de persistencia de los significados verbales es variable y una interjección suele tener varios usos en diferentes niveles del proceso de cambio. No obstante, este estudio ha demostrado que estos usos no son arbitrarios sino altamente motivados por el carácter semántico-pragmático de las formas verbales originarias.

En primer lugar, no es una casualidad que sean formas del imperativo de los verbos de movimiento que se han gramaticalizado hasta pertenecer a la categoría de las interjecciones. En los verbos de movimiento y en las formas verbales en general, desempeña un papel importante la deixis (tanto espacial, temporal, personal, social como textual). Como estas formas verbales están empapadas de deixis (verbos de dirección, morfema de persona, grado de formalidad, etc.) y los aspectos deícticos son subject to referential verification ('sumiso a verificación referencial') (cf. Traugott 1982) no es de extrañar que se presten a funcionar como interjecciones, unidades lingüísticas tan dependientes del co- y contexto.

En segundo lugar, las formas verbales en el modo imperativo se prestan a un reanálisis hasta la categoría de las interjecciones porque presentan algunas propiedades formales semejantas a las de las interjecciones. Así, como no llevan morfemas de tiempo y, además, el imperativo es un modo defectivo, son formas morfológicamente subdeterminadas y muchas veces relativamente breves. Muestran, encima, una gran libertad posicional y una relativa autonomía sintáctica, frente a otras formas verbales (cf. Pusch 2008, 3).

Conviene tomar en consideración los tres ejes de investigación que hemos propuesto en la introducción. Del estudio empírico se desprende que tanto el aspecto deíctico como el aspecto de movimiento de las formas verbales originarias son determinantes para las funciones que las interjecciones han desarrollado. Estos dos aspectos semánticos - que resultan, además, sumamente interrelacionados - se han extendido metafóricamente durante el proceso de cambio de las formas y han procurado que las interjecciones permitan desempeñar sus respectivos usos. El cuadro sinóptico sintetiza los aspectos semánticos principales en cuanto a la deixis y el 
movimiento, tanto como las extensiones metafóricas que influyen en las pobilidades funcionales de las interjecciones:

\begin{tabular}{|c|c|}
\hline La deixis & El movimiento \\
\hline $\begin{array}{l}\text { - deixis social: forma formal o } \\
\text { informal del verbo } \\
\text { deixis personal: la presencia o no } \\
\text { del oyente en la forma verbal } \\
>\text { 'vamos es colaborar' } \\
\text { deixis espacial: el movimiento } \\
\text { aferencial o } \\
\text { eferencial/acercamiento o } \\
\text { alejamiento del centro deíctico } \\
>\text { 'alejamiento/ acercamiento del lugar } \\
\text { donde está situado el hablante es } \\
\text { alejamiento/ acercamiento del tiempo del } \\
\text { bablante' (cf. Cifuentes Honrubias } \\
2007, \text { Traugott } 1978 \text { ). } \\
>\text { 'alejamiento del centro deíctico es } \\
\text { alejamiento de lo esencial' } \\
>\text { 'cambio imprevisto de resultado es } \\
\text { desviación' (cf. Radden 1995) }\end{array}$ & $\begin{array}{l}\text { - verbos de movimiento } \\
>\text { 'la mente como cuerpo' } \\
>\text { 'emoción es movimiento' } \\
>\text { 'cambio de estado es cambio de lugar' } \\
\text { (cf. Lakoff/Espenson/Schwartz } \\
\text { 1991) } \\
\text { - movimiento que implica una } \\
\text { dirección } \\
\text { > 'el discurso es un viaje' (cf. Romero } \\
\text { Aguilera } 2006 \text { ) } \\
>\text { 'argumentar es seguir una trayectoria' } \\
\text { (cf. Lakoff/Espenson/Schwartz } \\
\text { 1991) } \\
>\text { 'argumentos son trayectorias en las que } \\
\text { viajan pensamientos' } \\
\text { (cf. Lakoff/Espenson/Schwartz } \\
\text { 1991) } \\
>\text { 'cambio imprevisto de resultado es } \\
\text { desviación' (cf. Raddden 1995) } \\
>\text { 'cambio de estado es cambio de } \\
\text { dirección' (cf. Lakoff, Espenson y } \\
\text { Schwartz). } \\
\text { tiempo de referencia es tiempo de } \\
\text { salida o de llegada } \\
\text { Radden } 1995 \text { ) }\end{array}$ \\
\hline
\end{tabular}

Cuadro 4. Los aspectos semánticos y las metáfores de las formas verbales

Para empezar, las tres funciones centrales se dejan explicar fácilmente: (1) el uso apelativo proviene del modo imperativo de las formas verbales, (2) la metáfora que justifica los usos metadiscursivos de las interjecciones vamos, vaya y venga es 'el discurso es un viaje' ya que argumentar es seguir una trayectoria y (3) las metáforas 'emoción es movimiento' y 'cambio de estado es cambio de situación' que se inscriben dentro de la metáfora propuesta por Sweetser (1990) 'la mente como cuerpo', dan cuenta de los usos expresivos de las interjecciones. A pesar de estas extensiones metafóricas, se desprende del cuadro que entre los usos de las interjecciones y la semántica de las formas verbales originarias no existe una relación unívoca. Así, por ejemplo la deixis personal de vamos y la metáfora relacionada 'vamos es colaborar' pueden justificar varias de las posibilidades y restricciones funcionales de la interjección (aproximador, apoyo modal-enunciativo, etc.).

No obstante, hemos intentado proporcionar una visión general de los aspectos semánticos de las formas verbales que influyen en el comportamiento de las interjecciones derivadas sin pretender ser exhaustivas. Se da por supuesto que el tema abordado aquí merece un estudio más detallado y al mismo tiempo más amplio. En este sentido sería interesante explorar también otras interjecciones derivadas de formas verbales en español e incluso ampliar el estudio hacia otros idiomas para averiguar qué aspectos semánticos y extensiones metafóricas intervienen en el desarrollo de las interjecciones impropias. De esta manera, debe de ser posible trazar 
las metáforas principales que intervienen en los procesos de gramaticalización que generan interjecciones.

\section{Bibliografía}

Alarcos LLorach, Emilio, Gramática de la lengue española, Madrid, Espasa Calpe, 1994.

Alcaide Lara, Esperanza Rocío, Los operadores de modalidad, en: C. Fuentes Rodríguez (ed.), Introducción teórica a la Pragmática Lingüistica (Actas del Seminario de Pragmática Lingüistica, Sevilla, Febrero 1996), Sevilla, Kronos, 73-86, 1996.

Almela Pérez, Ramón, Apuntes gramaticales sobre la interjección, Murcia, Universidad de Murcia, 1990.

Alonso-Cortés, Ángel, Las construcciones exclamativas. La interjección y las expresiones vocativas, en: Ignacio Bosque y Violeta Demonte (edd.), Gramática descriptiva de la lengua española, Madrid: Real Academia Española/ Espasa Calpe, 3994-4050, 1999.

Anscombre, Jean-Claude y Ducrot, Oswald, La argumentación en la lengua, Madrid, Gredos, 1994.

Briz Gómez, Antonio, Hacia un análisis argumentativo de un texto coloquial. La incidencia de los conectores pragmáticos, Verba 21, 369-395, 1994.

Briz Gómez, Antonio, El español coloquial en la conversación. Esbozo de pragmagramática, Barcelona, Arial, 1998.

Briz Gómez, Antonio, Corpus de conversaciones coloquiales, Madrid, Arco Libros, 2002.

Briz Gómez, Antonio et al., el diccionario de partículas discursivas del español http://textodigital.com/P/DDPD/, 2008.

Brown, Penelope y Levinson, Stephen C., Politeness: Some universals in language usage, Cambridge, Cambridge University Press, 1987.

Bühler, Karl, Teoría del lenguaje, Madrid, Revista de Occidente, 1950.

Cifuentes Honrubia, José Luis, Verbos deícticos en español, en: Cuniță, A, Lupu, C. y Tasmowski, L. (edd.), Studii de Lingvistică şi Filologie Romanică: Hommages offerts à Sandra Reinheimer Rippeanu, Bucarest, Universidad de Bucarest, 99-112, 2007.

Company Company Concepción, ¿Gramaticalización o desgramaticalización? El reanálisis y subjetivización de verbos como marcadores discursivos en la historia del español, Revista de Filología Española, 84, No. 1, 29-66, 2004.

Company Company, Concepción, The directionality of grammaticalization in Spanish, en: Journal of Historical Pragmatics 9:2, 200-224, 2008.

Cortés Rodríguez, Luis, Sobre conectores, expletivos y muletillas en el español hablado, Málaga, Ágora, 1991.

Crego García, María Victorina, El complemento locativo en español. Los verbos de movimiento y su combinatoria sintáctico-semántica, Santiago de Compostela, Universidad de Santiago de Compostela, 2000.

Cuenca, María José, Sintaxi fonamental, Barcelona, Empúries, 1996.

Cuenca, María José y Hilferty, Joseph, Introducción a la lingüística cognitiva, Barcelona, Ariel, 1999

Cuenca, María José, Defining the indefinable? Interjections, en: Syntaxis. An International Journal of Syntactic Research, 3, 29-44, 2000.

Cueto Vallverdú, Natalia/López Bobo/Maria Jesús, La interjección: semántica y pragmática. Madrid: Arco/Libros, 2003. 
Davies, Mark., Corpus del español, http://www.corpusdelespanol.org., 2001-. Dobrushina, N./Goussev, V., Inclusive imperative, en: Clusivity: typology and case studies of the inclusive-exclusive distinction, Philadelphia, John Benjamins, 179-211, 2005.

Dostie, Gaétane, Pragmaticalisation et marqueurs discursifs: analyse sémantique et traitement lexicographique, Bruselas, De Boeck Duculot, 2004.

Edeso Natalías, Verónica, Contribución al estudio de la interjección en español, Frankfurt am Main, Lang, 2009.

Fuentes Rodríguez, Catalina, V amos: un conector coloquial de gran complejidad, en: Martín Zorraquino y Montolío Durán, E. (edd.), Marcadores del discurso. Teoría y análisis, Madrid, Arco/ Libros, 177-192, 1998.

González Ollé, Fernando, Vamos. De subjuntivo a marcadores (con un excurso sobre imos), en: Pedro Alvarez de Miranda/José Polo Polo (edd.), estudios ofrecidos a Manuel Seco, Madrid, Arco/Libros, 117-135, 2002.

Haverkate, Henk, La cortesía verbal: estudio pragmalingüístico, Madrid, Gredos, 1994. Heine, Claudi y Hunnemeyer, Grammaticalization University of Chicago Press, 1991.

Hopper, Paul Joseph/Elizabeth Closs Traugott., Grammaticalization, Cambridge, England, Cambridge University Press, 1993.

Jakobson, Roman, Closing statements: Linguistics and Poetics, en: T.A. Sebeok (ed.), Style in Language, First edition, MIP Press, Cambridge Massachusetts, 350-377, 1960.

Lakoff, George, Espenson, Jane /Schwartz Alan, Master Metaphor List, http:/ / araw.mede.uic.edu/ alansz/metaphor/METAPHORLIST.pdf, 1991.

Landone, Elena, Los marcadores del discurso y la cortesía verbal en español, New York, Peter Lang, 2009.

Langacker, Ronald Wayne, Foundations of cognitive grammar 1: Theoretical prerequisites, Stanford, Stanford University Press, 1987.

Levinson, Stephen C., Pragmatics, Cambridge, Cambridge university press, 1983.

López Bobo, Maria Jesús, La interjección: aspectos gramaticales. Madrid: Arco/Libros, 2002.

Marín Jordà, María Josep, Marcadors discursius procedents de verbs de percepció. Argumentació implícita en el debat electoral, Valencia, Arts Gràfiques Soler, S.L., 2005.

Martín Zorraquino, María Antonia y Portolés, José, Los marcadores del discurso, en: Bosque, I. y Demonte, V. (edd.), Gramática descriptiva de la lengua española, 40514213, 1999.

Martins Valle, Carla Regina, Marcadores discursivos: Consideraçôes sobre os limites entre a gramaticalização e a discuisiviz̧ação, en: Working Papers em Lingüística 4:104-113, 2000.

Nakazawa, Tsuneko, A typology of the ground of deictic motion verbs as path-conflating verbs: the speaker, the addresse, and beyond, en: Pozán Studies in Contemporary Linguistics 43(2), 59-82, 2006.

Ocampo, Fransisco, Movement Towards Discourse Is not Grammaticalization: The evolution of claro form adjective to discourse particle in spoken Spanish, en: Nuria Sagarra/Almeida Jacqueline Toribio (edd.), Selected Proceedings of the 9th Hispanic Linguistics Symposium, 308-319. Somerville, MA: Cascadilla Proceedings Project, 2006.

Octavio de Toledo y Huerta, Álvaro Sebastián, ¿Un viaje de ida y vuelta?: la gramaticalización de vaya como marcador y cuantificador, en: Anuari de filologia XXIII-XIV, 47-71, 2001-2002.

Pons Bordería, Salvador, Conexión y conectores: estudio de su relación en el registro informal de la lengua, Cuadernos de Filología, Valencia, Universitat de València, 1998.

Pons Rodríguez, Lola, Los marcadores del discurso en la historia del español, en: Oscar Loureda Lamas y Esperanza Acín Villa (edd.), Los estudios sobre marcadores del discurso en español, hoy. Madrid: Arco/Libros, 2010.

Portolés, José, La teoría de la argumentación en la lengua y los marcadores del discurso, en: Martín Zorraquino, M. A./ Montolío Durán, E (edd.), Marcadores del discurso. Teoría y análisi, Madrid, Arco Libros, 71-91, 1998. 
Portolés, José, Marcadores del discurso, Barcelona, Ariel, 2001.

Pusch, Claus D., Marqueurs discursifs et subordination syntaxique: La Construction inférentielle en français et dans d'autres langues romanes, bttp:/ / www.romanistik.unifreiburg.de/pusch/Download/ construction_inferentielle.pdf, 2008.

Radden, Günter, Motion metaphorized: the case of coming and going, en: Casad, E. H. (ed.), Cognitive linguistics in the Redwoods: The Expansion of a new paradigm in Linguistics, Mouten De Gruyter, 423-458, 1995.

Real Academia Española: Banco de datos (CREA). Corpus de referencia del español actual. <http://www.rae.es>.

Real Academia Española: Diccionario de la lengua española, http:/ /www.rae.es/rae.html.

Rodríguez Ramalle, Teresa María, Las interjecciones llevan complementos, jvaya que sí! Análisis de las interjecciones con complemento en el discurso, en: Español actual 87, 111-125, 2007.

Romero Aguilera, Laura, La gramaticalización de verbos de movimiento como marcadores del discurso, en: Res Diachronicae 5, 46-56, 2006.

Samper Padilla, José Antonio et al., Macrocorpus de la norma lingüistica culta de la principales ciudades del mundo bispánico [MC-NLCH] (recurso electrónico), Las Palmas de Gran Canaria, Universidad de Las Palmas de Gran Canaria, 1998.

Sancho Cremades, Pelegrí, Construcciones idiomáticas e ironía: el español anda que no y el valenciano coloquial diràs que no, en: Análisis del discurso: lengua, cultura, valores: actas del I congreso internacional II, 2051-2065, 2006 .

Sancho Cremades, Pelegrí, Interjecciones intensificadores en español y en catalán, en: Lingǘstica Española Actual XXVIII/1, 91 - 133, $2006 \mathrm{~b}$.

Santos Río, Luis, Diccionario de partículas, Salamanca, Luso-Española de ediciones, 2003.

Solano Rojas, Yamileth, Los conectores pragmáticos en el habla culta costarricense, en: Revista de Filología y Lingüística de la Universidad de Costa Rica, XV, 2, 1989.

Sweetser, Eve, From etymology to pragmatics: metaphorical and cultural aspects of semantic structure, Cambridge, Cambridge university press, 1990.

Tanghe, Sanne (en prensa), Acerca de los intensificadores vaya y qué: un estudio comparativo de corpus, en: Bulletin of Hispanic Studies.

Tenny, Carol, How motion verbs are special: the interaction of semantic and pragmatic information is aspectual verb meanings, en: Pragmatics \& cognition, John Benjamins Publishing, 31-73, 1995.

Torres Sánchez, Maria Ángeles, La interjección. Cádiz: Universidad de Cádiz.Servicio de publicaciones, 2000.

Traugott, Elizabeth Closs, On the expression of spatio-temporal relations in language, en: Greenberg, J.H. (ed.), Universals of human language: Vol.3. Word structure, 369-400, 1978.

Traugott, Elizabeth Closs, From propositional to textual to expressive meanings: Some semantic pragmaticaspects of grammaticalization, en: Lehmann,W.P./Malkiel, Y. (edd.), Perspectives on Historical Linguistics, Amsterdam, John Benjamins, 245 $271,1982$.

Traugott, Elizabeth Closs /König, Ekkehard, The semantics-pragmatics of grammaticalization revisited, en: Traugott, E.C./Heine, B. (edd.), Approaches to grammaticalization, Amsterdam: Benjamins, 189-218, 1991.

Traugott, Elizabeth Closs /Dasher, Richard B., The development of adverbials with discourse marker function, en: Regularity in semantic change, Cambridge, Cambridge university press, 152-189, 2002.

Vázquez Veiga, Nancy, Marcadores discursivos de recepción, Santiago de Compostela, Universidad de Santiago de Compostela, 2003. 
